\title{
Mental health screening in armed forces before the Iraq war and prevention of subsequent psychological morbidity: follow-up study
}

Roberto J Rona, Richard Hooper, Margaret Jones, Lisa Hull, Tess Browne, Oded Horn, Dominic Murphy, Matthew Hotopf, Simon Wessely

\begin{abstract}
Objective To assess whether screening for mental disorder before the start of the 2003 Iraq war would have predicted subsequent mental disorders.

Design Longitudinal cohort study of the United Kingdom armed forces.

Participants 2820 of 2873 personnel of the three services who completed an initial questionnaire in 2002 were asked to complete a second questionnaire between June 2004 and 2 March 2006.

Setting Regiments, air stations, bases, ships, and homes for those who had left the services.

Main outcome measures Positive and negative likelihood ratios, and positive and negative predictive value of first assessment compared with assessment two to three years later of post-traumatic stress disorder, general health questionnaire, physical symptoms, self perception of health, and alcohol misuse for the entire group and for those deployed to the Iraq war.

Results The response rate to the follow-up questionnaire was $69 \%$, adjusted for return to senders. The positive likelihood ratio of post-traumatic stress disorder was high (13.1, 95\% confidence interval 7.2 to 23.8 ), but the negative likelihood ratio was close to $1(0.78,0.67$ to 0.91$)$. The positive predictive values were low because of the low prevalence of post-traumatic stress disorder in the period before the Iraq war. The positive likelihood ratios for the other psychological assessments varied between 2.7 and 5.6, and the negative likelihood ratios were slightly lower than for post-traumatic stress disorder, indicating that these were not good candidates for screening. Results were the same for the analyses restricted to those who were deployed.

Conclusions Screening for common mental disorders before deployment in this cohort would not have reduced subsequent morbidity or predicted post-traumatic stress disorder, but this may change if there is a considerable increase in the prevalence of the disorder.
\end{abstract}

\section{Introduction}

Psychological syndromes after combat have been a feature of many wars. ${ }^{12}$ As these syndromes are common and associated with morbidity and considerable costs, there have been calls for the implementation of screening programmes to detect and exclude those who are psychologically vulnerable before they are deployed. ${ }^{34}$ At the start of the second world war there was a strong belief that excluding those who were psychologically vul- nerable would greatly decrease the proportion of psychiatric casualties after deployment. ${ }^{15-7}$ The programme was a costly failure, and, despite high rates of rejection on the basis of presumed psychological vulnerability, the rates of psychiatric breakdown in the field were comparable with or even greater than those observed in the first world war. ${ }^{8}$

Few recent reports have been published on the association between assessments of mental disorders in the armed forces before and after deployment. Those published relate to the impact of personality before deployment on post-traumatic stress disorder after deployment ${ }^{10}{ }^{11}$ or have been small longitudinal studies in which post-traumatic stress disorder or physical symptoms before deployment were among a series of predictors. ${ }^{12}$ Studies carried out more than 50 years ago showed that, although there was a higher failure rate among those who were initially rejected on psychiatric grounds but later enlisted, or about whom doubts were expressed, nearly all performed satisfactorily. ${ }^{13-17}$

In 2002 we assessed the acceptability of screening questionnaires for psychological illness and the validity of these questionnaires, using as the "gold standard" the opinion of medical officers (equivalent to general practitioners) in a random sample of the British armed forces in the period immediately before preparations for the Iraq war began. ${ }^{11} 19$ A proportion of participants in our study were subsequently deployed to Iraq. We contacted the participants in our initial study, including those who were deployed, to assess the value of such screening before deployment in predicting mental disorders after deployment using the same measurements for post-traumatic stress disorder, general psychological health, physical symptoms, self perception of health, and excessive alcohol use. We also analysed those who were not deployed to Iraq, most of whom have been on other recent deployments, ${ }^{18}$ to assess the general predictability of psychological tests in the armed forces.

\section{Methods}

\section{Sampling}

In 2002, two groups were randomly selected to receive a full or an abridged screening questionnaire to assess psychological health. Services were represented by their relative strength at July 2001. Units were randomly selected, and 45 individuals were randomly selected from each unit. The study had a response rate of $67 \%(n=2873)$ among those with a valid address $(n=4304) .{ }^{18}$ From June 2004 to 2 March 2006 we asked 2820 of the 2873 who completed the initial questionnaire to complete a second questionnaire. This follow-up study was carried out simultane- 
Table 1 Criteria for referral to medical centres according to length of the questionnaire

\begin{tabular}{lll} 
Dimension & \multicolumn{1}{c}{ Full questionnaire } & \multicolumn{1}{c}{ Abridged questionnaire } \\
\hline Symptoms & $\begin{array}{l}\geq 5 \text { mild or combinations of mild and } \\
\text { moderate; } \geq 3 \text { moderate; at least } 1 \text { severe } \\
\text { symptom }\end{array}$ & $\begin{array}{l}\text { At least } 3 \text { mild or moderate } \\
\text { symptoms or at least } 1 \text { severe } \\
\text { symptom }\end{array}$ \\
\hline GHQ & GHQ-12 with score of $\geq 4$ & GHQ-4 with score of $\geq 2$ \\
\hline PTSD & 17 items with score of $\geq 50$ & 14 items with score of $\geq 40$ \\
\hline Health status & Poor or fair & Poor or fair \\
\hline Alcohol intake & $\begin{array}{l}\geq 40 \text { units/week in men and } \geq 30 \text { in } \\
\text { women, or if somebody expressed } \\
\text { concern with individual's drinking in past } \\
\text { year }\end{array}$ & Not applicable \\
\hline
\end{tabular}

$\mathrm{GHQ}=$ general health questionnaire; $\mathrm{PTSD}=$ post-traumatic stress disorder.

ously with a larger cross sectional study aimed at comparing the health outcomes of those deployed to Iraq and those not deployed.$^{20}$ The methods of tracing and recruiting the two samples were identical and were done simultaneously. Full details are given elsewhere.$^{20}$ Participants could complete the questionnaire at a base visit or by post. Non-responders received two further mailings and were further traced through their unit or through electoral registers, telephone directories, or the National Strategic Tracing Service for those who had left the services. ${ }^{20}$

The United Kingdom deployment to Iraq is code named Operation Telic and is divided into several phases. If personnel were deployed between 18 January and 28 April 2003 they belonged to Operation Telic 1; if they were deployed from the 29 April or later they belonged to Operations Telic 2 to 6 ; if they were not deployed to the Iraq war they were included in the Era group. The cohort includes only regular personnel, some of whom left the forces during the study.

\section{Information}

The full 2002 questionnaire (baseline) included the civilian version of the post-traumatic stress disorder checklist (PCL-C), ${ }^{21}$ the general health questionnaire 12 (GHQ-12) as a measure of psychological distress, ${ }^{22} 15$ physical symptoms selected from a previously used questionnaire, ${ }^{23}$ a self assessment of health status from the SF-36, ${ }^{24}$ and three questions from the World Health Organization's alcohol use disorders identification test questionnaire (WHO Audit) to assess alcohol use. ${ }^{25}$ The abridged 2002 questionnaire included a post-traumatic stress disorder checklist, reduced from 17 to 14 items, a selection of four items from the GHQ-12 following published criteria, ${ }^{26}$ five of the 15 symptoms of the full questionnaire, and a question on self perception of health. We excluded questions on alcohol use.

The questionnaire administered after deployment included the full version of the same psychological scales used in the previous study but included 53 physical symptoms. Information was also obtained on sex, age, rank, the number of previous deployments, and, in the initial survey, medical downgrading. Medical downgrading refers to the system of assessment of fitness and employability of service personnel based on a medical examination. The participants were informed about the aims of the study, reassured about confidentiality, informed that they were under no obligation to participate, and provided with contact information to discuss any queries.

Table 1 shows the criteria for caseness for the psychological scales. These were at variance with our previous publication ${ }^{18}$ in so far as GHQ-12 cases were those scoring $\geq 4$, as in most epidemiological studies. ${ }^{20}{ }^{23}$ We also merged poor and fair self perception of health as the lower health status group. In the analysis of symptoms we considered only the 15 symptoms common to both surveys.
Table 2 Baseline characteristics of responders and non-responders at follow-up. Figures show numbers (percentage) unless stated otherwise

\begin{tabular}{|c|c|c|}
\hline & Responders ( $n=1885$ ) & Non-responders $(n=935)$ \\
\hline \multicolumn{3}{|l|}{ Service: } \\
\hline Navy & $444(23.6)$ & $234(25.0)$ \\
\hline Army & $909(48.2)$ & $420(45.0)$ \\
\hline RAF & $532(28.2)$ & $281(30.0)$ \\
\hline \multicolumn{3}{|c|}{ Deployments in previous three years: } \\
\hline None & $787(41.8)$ & $406(43.4)$ \\
\hline 1 country & $637(33.8)$ & $303(32.4)$ \\
\hline$>1$ country & $461(24.5)$ & 226 (24.3) \\
\hline Rank below officer & $1460(77.5)$ & 771 (82.5) \\
\hline Mean (SD) age (years) & $33.0(7.7)$ & $31.4(8.0)$ \\
\hline Men & $1742(92.3)$ & $856(91.5)$ \\
\hline Medically downgraded & $228(12.1)$ & $122(13.0)$ \\
\hline \multicolumn{3}{|c|}{ Cases (from both questionnaires*) according to: } \\
\hline GHQ & $381(20.2)$ & $195(20.8)$ \\
\hline PTSD & $45(2.4)$ & $32(3.4)$ \\
\hline Symptoms & $308(16.3)$ & $143(15.3)$ \\
\hline Self perception of health & $223(11.8)$ & 115 (12.3) \\
\hline \multicolumn{3}{|c|}{ Cases† (from full questionnaire) according to: } \\
\hline GHQ & $185(19.7)$ & $85(20.3)$ \\
\hline PTSD & $21(2.2)$ & $11(2.6)$ \\
\hline Symptoms & $288(30.6)$ & $126(30.1)$ \\
\hline Alcohol misuse & $102(10.8)$ & 69 (16.5) \\
\hline
\end{tabular}

$\mathrm{GHQ}=$ general health questionnaire; $\mathrm{PTSD}=$ post-traumatic stress disorder.

*From full and abridged questionnaires, using questions common to both

†ln 941 responders and 418 non-responders.

\section{Analysis}

We assessed the validity of the baseline questionnaire in predicting mental disorders in the follow-up questionnaire (end point assessment) in terms of sensitivity, specificity, positive and negative predictive values of the test, and positive and negative likelihood ratios. ${ }^{27}$ The analysis was carried out for the subgroup with complete psychological scales and for the total sample by using the items common to the full and abridged questionnaires. The validity assessment was carried out for the total sample, for Era plus Telic, and, separately, for those in Telic 1 to Telic 6 . We used this approach because Telic is only one of several deployments at any point in time. We show the results comparing the same items before and after deployment.

\section{Results}

The response rate was 1885 (67\%), being higher in officers and older personnel (table 2). Psychological health variables in the initial assessment did not predict non-response in the second survey. Among those who completed the questionnaire, there were relatively more Royal Navy personnel in the Era group than in the two Telic groups and relatively more army personnel in Telic 2-6 (table 3). The percentage of medically downgraded personnel before deployment was lower in Telic than Era. The mean age was lower in Telic 2-6 than the other two groups. Caseness according to GHQ, symptoms, and health perception was more common before deployment in the Era than in the Telic groups, but alcohol misuse was higher in the Telic groups.

We assessed whether caseness before the Iraq war predicted caseness later using items common to the full and abridged questionnaires and for those who completed only the full questionnaire (table 4). With a few exceptions, both analyses gave similar results. The positive likelihood ratio was higher for posttraumatic stress disorder than for the other psychological assessments, though the 95\% confidence intervals were wide. The negative likelihood ratio for post-traumatic stress disorder was 
Table 3 Characteristics of respondents according to deployment on Telic operations. Figures show numbers (percentages) unless stated otherwise

\begin{tabular}{|c|c|c|c|}
\hline & Era $(n=1216)$ & Telic 1 ( $n=383)$ & Telic 2-6 $(n=286)$ \\
\hline \multicolumn{4}{|l|}{ Baseline } \\
\hline \multicolumn{4}{|l|}{ Service: } \\
\hline Navy & $353(29.0)$ & $60(15.7)$ & $31(10.8)$ \\
\hline Army & $557(45.8)$ & $192(50.1)$ & $160(55.9)$ \\
\hline RAF & $306(25.2)$ & $131(34.2)$ & $95(33.2)$ \\
\hline Ranked below officers & $946(77.8)$ & $286(74.7)$ & $228(79.7)$ \\
\hline Mean (SD) age (years) & $33.8(7.7)$ & $32.2(7.0)$ & $30.8(7.2)$ \\
\hline Men & $1115(91.7)$ & $359(93.7)$ & $266(93.0)$ \\
\hline Medically downgraded & $160(13.2)$ & $40(10.4)$ & $28(9.8)$ \\
\hline \multicolumn{4}{|c|}{ Cases (from both questionnaires*) according to: } \\
\hline $\mathrm{GHQ}$ & $270(22.2)$ & $64(16.7)$ & $47(16.4)$ \\
\hline PTSD & $32(2.6)$ & $6(1.6)$ & $7(2.4)$ \\
\hline Symptoms & $212(17.4)$ & $55(14.4)$ & $41(14.3)$ \\
\hline Self perception of health & $153(12.6)$ & $37(9.7)$ & $33(11.5)$ \\
\hline \multicolumn{4}{|c|}{ Cases† (from full questionnaire) according to: } \\
\hline GHQ & $138(22.5)$ & $27(15.9)$ & $20(12.7)$ \\
\hline PTSD & $13(2.1)$ & $3(1.8)$ & $5(3.2)$ \\
\hline Symptoms & $196(31.9)$ & $49(28.8)$ & $43(27.4)$ \\
\hline Alcohol misuse & $59(9.6)$ & $20(11.8)$ & $23(14.6)$ \\
\hline \multicolumn{4}{|c|}{ Cases at follow-up according to measure } \\
\hline GHQ & $240(19.7)$ & $64(16.7)$ & $54(18.9)$ \\
\hline PTSD & $37(3.0)$ & $5(1.3)$ & $9(3.1)$ \\
\hline Symptoms & $387(31.8)$ & $104(27.2)$ & $82(28.7)$ \\
\hline Self perception of health & $162(13.3)$ & $44(11.5)$ & $37(12.9)$ \\
\hline Alcohol misuse & $154(12.7)$ & $76(19.8)$ & $47(16.4)$ \\
\hline
\end{tabular}

Era=personnel not deployed to Iraq; Telic $1=$ personnel deployed to Iraq 18 January to 28 April 2003; Telic 2-6=personnel deployed to Iraq 29 April 2003 or later. GHQ=general health questionnaire; PTSD=post-traumatic stress disorder.

*From full and abridged questionnaires, using questions common to both.

†In 614 in Era, and 170 in Telic 1 and 157 in Telic 2-6. only 0.78 . For the other psychological assessments, the positive likelihood ratio was between 2.7 and 5.6, and the negative likelihood ratio was between 0.55 and 0.69 . The negative likelihood ratio for alcohol misuse was only slightly below 1 , indicating a low predictability in those who did not drink to excess before. The sensitivity values were low, especially for post-traumatic stress disorder, and specificity values were high, especially for post-traumatic stress disorder and alcohol misuse. The positive predictive value for post-traumatic stress disorder was low because it was uncommon. The negative predictive value for post-traumatic stress disorder was high, indicating that an initial score below the threshold for post-traumatic stress disorder would tend to remain below. For the other psychological assessments the positive predictive value was higher than for post-traumatic stress disorder, but the negative predictive value was much lower.

We repeated the analysis restricting it to Telic 1-6 (table 5). With the exception of post-traumatic stress disorder, the values were similar to the previous analysis. The positive likelihood ratio of post-traumatic stress disorder was similar only in those who completed the full questionnaire at baseline.

\section{Discussion}

\section{Main findings}

This study provides little support for the use of mental health screening before deployment for preventing mental disorders after deployment. For every psychological assessment either the positive predictive value or the negative predictive value was low. The positive likelihood ratio for post-traumatic stress disorder was much higher than for any other psychological assessment, but as the disorder was uncommon $(<3.2 \%)$ even with a relatively high positive likelihood ratio the positive predictive

Table 4 Caseness at baseline as a predictor of caseness at follow-up in total cohort ( $n=1885)$ : likelihood ratios, sensitivity, specificity, and positive and negative predictive values (with 95\% confidence intervals)

Positive likelihood ratio Negative likelihood ratio Sensitivity Specificity Positive predictive value Negative predictive value Full and abridged questionnaires (using questions common to both):

\begin{tabular}{|c|c|c|c|c|c|c|}
\hline GHQ & 2.7 (2.3 to 3.2$)$ & 0.69 (0.63 to 0.75$)$ & 0.42 (0.36 to 0.47$)$ & 0.85 (0.83 to 0.87$)$ & 0.39 (0.34 to 0.44$)$ & 0.86 (0.84 to 0.88$)$ \\
\hline PTSD & 13.1 (7.2 to 23.8$)$ & 0.78 (0.67 to 0.91$)$ & 0.24 (0.13 to 0.37$)$ & 0.98 (0.97 to 0.99$)$ & 0.27 (0.15 to 0.42$)$ & 0.98 (0.97 to 0.98$)$ \\
\hline Symptoms & 4.8 (3.8 to 5.9$)$ & $0.69(0.65$ to 0.73$)$ & 0.36 (0.32 to 0.40$)$ & 0.92 (0.91 to 0.94) & 0.68 (0.62 to 0.73$)$ & 0.77 (0.75 to 0.79$)$ \\
\hline $\begin{array}{l}\text { Self perception of } \\
\text { health }\end{array}$ & 5.6 (4.5 to 7.0$)$ & 0.63 (0.57 to 0.70$)$ & 0.42 (0.35 to 0.48$)$ & 0.93 (0.91 to 0.94) & 0.45 (0.39 to 0.52$)$ & 0.91 (0.90 to 0.93$)$ \\
\hline \multicolumn{7}{|l|}{ Full questionnaire: } \\
\hline GHQ & 3.2 (2.6 to 4.1$)$ & 0.64 (0.56 to 0.73$)$ & 0.45 (0.37 to 0.52$)$ & 0.86 (0.84 to 0.89$)$ & 0.44 (0.37 to 0.51$)$ & 0.87 (0.84 to 0.89$)$ \\
\hline PTSD & 16.3 (7.1 to 37.2$)$ & 0.76 (0.61 to 0.94$)$ & 0.25 (0.11 to 0.45$)$ & 0.98 (0.97 to 0.99$)$ & 0.33 (0.15 to 0.57$)$ & 0.98 (0.97 to 0.99$)$ \\
\hline Symptoms & 2.9 (2.4 to 3.5$)$ & 0.55 (0.48 to 0.63$)$ & 0.56 (0.50 to 0.62 ) & 0.81 (0.78 to 0.84$)$ & 0.57 (0.51 to 0.63 ) & 0.80 (0.77 to 0.83$)$ \\
\hline Alcohol misuse & 4.4 (3.1 to 6.3 ) & 0.74 (0.66 to 0.82 ) & $0.32(0.24$ to 0.40$)$ & 0.93 (0.91 to 0.95$)$ & $0.44(0.34$ to 0.54$)$ & 0.88 (0.86 to 0.91$)$ \\
\hline
\end{tabular}

$\mathrm{GHQ}=$ general health questionnaire; $\mathrm{PTSD}=$ post-traumatic stress disorder.

Table 5 Caseness at baseline as a predictor of caseness at follow-up in Telic cohorts ( $n=669)$ : likelihood ratios, sensitivity, specificity, and positive and negative predictive values (with 95\% confidence intervals)

Positive likelihood ratio Negative likelihood ratio

Sensitivity

Specificity Positive predictive value Negative predictive value

Full and abridged questionnaires (using questions common to both):

\begin{tabular}{|c|c|c|c|c|c|c|}
\hline GHQ & 2.6 (1.9 to 3.7$)$ & 0.76 (0.66 to 0.87$)$ & 0.34 (0.25 to 0.43$)$ & 0.87 (0.84 to 0.90$)$ & 0.36 (0.27 to 0.46$)$ & 0.86 (0.83 to 0.89 ) \\
\hline PTSD & $3.9(0.5$ to 28.0$)$ & 0.95 (0.82 to 1.09$)$ & 0.07 (0.00 to 0.34$)$ & 0.98 (0.97 to 0.99) & 0.08 (0.00 to 0.36$)$ & 0.98 (0.97 to 0.99 ) \\
\hline Symptoms & 4.7 (3.2 to 7.0$)$ & $0.72(0.65$ to 0.80$)$ & 0.33 (0.27 to 0.41$)$ & 0.93 (0.90 to 0.95$)$ & 0.65 (0.54 to 0.74$)$ & 0.78 (0.75 to 0.82$)$ \\
\hline $\begin{array}{l}\text { Self perception of } \\
\text { health }\end{array}$ & 6.5 (4.3 to 9.8$)$ & 0.63 (0.53 to 0.76$)$ & 0.41 (0.30 to 0.52$)$ & 0.94 (0.91 to 0.96$)$ & 0.47 (0.35 to 0.59$)$ & $0.92(0.90$ to 0.94$)$ \\
\hline \multicolumn{7}{|l|}{ Full questionnaire: } \\
\hline GHQ & 3.2 (1.9 to 5.3) & 0.74 (0.62 to 0.90$)$ & 0.33 (0.21 to 0.47$)$ & 0.90 (0.85 to 0.93$)$ & $0.40(0.26$ to 0.56$)$ & 0.86 (0.82 to 0.90$)$ \\
\hline PTSD & 13.3 (3.2 to 56.0$)$ & 0.76 (0.51 to 1.14$)$ & 0.25 (0.03 to 0.65$)$ & 0.98 (0.96 to 0.99$)$ & 0.25 (0.03 to 0.65$)$ & 0.98 (0.96 to 0.99$)$ \\
\hline Symptoms & 3.5 (2.5 to 5.0$)$ & 0.52 (0.41 to 0.65$)$ & 0.57 (0.46 to 0.67$)$ & 0.84 (0.79 to 0.88$)$ & 0.60 (0.49 to 0.70$)$ & 0.82 (0.77 to 0.87$)$ \\
\hline Alcohol & 2.9 (1.7 to 5.0$)$ & 0.80 (0.68 to 0.93$)$ & 0.28 (0.17 to 0.40$)$ & 0.90 (0.86 to 0.94$)$ & $0.42(0.27$ to 0.58$)$ & 0.83 (0.79 to 0.88$)$ \\
\hline
\end{tabular}

$\mathrm{GHQ}=$ general health questionnaire; $\mathrm{PTSD}=$ post-traumatic stress disorder. 
value was low. The negative likelihood ratio showed low predictability of a negative case at baseline. Our findings indicate that although there is a meaningful relation between the results of each test before and after the war, the levels of predictability were too low to infer a persistent mental health state.

Our study is unique in that we had data on mental health status in a randomly selected sample of the British armed forces just before planning started for the Iraq war. Thus the assessment before deployment was not coloured by anticipatory anxiety or exhilaration, both commonly seen before deployment. ${ }^{28}$ Screening before and after deployment has been implemented by the US Department of Defense, but longitudinal assessments are unavailable. ${ }^{28}{ }^{29}$ Analysis before and after deployment has been compared from separate cross sectional analyses. ${ }^{20}$ Such an analysis allows the assessment of net changes, assuming that the samples before and after deployment are similar, but it does not allow analysis within individuals. A limitation of our study is the response rate of about $70 \%$, although this compares favourably with other studies in the military ${ }^{30}$ and is as expected considering the high mobility of young military personnel and a high rate of turnover. ${ }^{20}$ Possible bias associated with non-completion of the questionnaire cannot be eliminated but those with a possible mental disorder at baseline had a similar response rate in the follow-up to the rest.

The response rate was lower in the Era sample than the deployed sample because the proportion of personnel who had left the armed forces was higher in the Era sample. Personnel who have left the services are less likely to take part, especially if they are disaffected because of their service experiences.

\section{The findings in context}

Our results should be interpreted in the light of an ongoing discussion of the merits of screening before deployment. ${ }^{14143132}$ Such screening for assessing mental health before a major conflict has been an issue since the first world war. ${ }^{12}$ Many doctors testifying to the Southborough Committee after the first world war expressed the view that it was irresponsible not to assess recruits' mental health before enlistment. ${ }^{2}$ The shared view was that vulnerable people should not become combatants. The US started a vigorous screening programme to assess mental health in the second world war, but the instruments used were heterogeneous and poorly validated. ${ }^{2}$ After a memorandum from General George C Marshall, alarmed by the large number of enlisted personnel lost compared with the number of newly drafted personnel, screening before enlistment was stopped. ${ }^{2}$ The same dilemma has emerged recently. In the US a serious attempt has been made to develop a battery of psychological tests to be used for screening. ${ }^{29}{ }^{31}$ This may have been influenced by the high rates of post-traumatic stress disorder in the US armed forces deployed in Iraq-18\% in the army and nearly $20 \%$ in the marines, in contrast with $4 \%$ of the UK armed forces. ${ }^{20} 28$

Our results suggest that psychological symptoms tend to persist for all our measures regardless of deployment. With the exception of post-traumatic stress disorder, however, the likelihood ratios, positive and negative, suggest implementation of a screening programme would be an imperfect way of identifying individuals with mental health symptoms. Our results are equivalent to those published over 50 years ago that showed that although there was an association between those originally identified as unsuitable to serve in the armed forces, over time most had only sporadic problems. ${ }^{13}{ }^{14}$ Caseness related to the general health questionnaire, physical symptoms, and alcohol misuse is common in the civilian population and in the military. The application of these tests for screening would create great difficulties given the stigma associated with mental health problems, ${ }^{18}{ }^{28}$ have serious resource implications, develop an unsustainable staffing shortage, and might have an adverse effect on morale.

The issue of post-traumatic stress disorder deserves a separate discussion. The positive likelihood ratio for posttraumatic stress disorder was relatively high, but the confidence intervals were too wide to assume that a diagnosis can be ruled in or out with confidence. This would mean that those identified as having post-traumatic stress disorder would have persistent symptoms over time. The negative likelihood ratio was barely below 1 , however, denoting that not being a case had low predictive value. This result makes sense because it has already been shown that vulnerability factors usually have low effect size for post-traumatic stress disorder, in contrast with the response to a traumatic event. ${ }^{33}$ Without considering the effectiveness of treating the condition, the main issue is whether it is worth screening for post-traumatic stress disorder given a positive likelihood ratio of 13 or 16 (depending on questionnaire). The low positive predictive value, resulting from the current low prevalence of the condition, indicates that it would be unwise to implement a screening programme.

It is our contention that screening for several mental disorders and psychosocial difficulties, as proposed by Bliese and colleagues, ${ }^{31}$ is fraught with problems. Common psychological complaints that do not persist over time should not be considered as good candidates for screening. On the other hand, post-traumatic stress disorder, which can be persistent, might be a better candidate provided its prevalence is sufficiently high. ${ }^{34} \mathrm{~A}$ high prevalence of the disorder is being reported from the US, ${ }^{31}$ though it is less prevalent in the UK armed forces. ${ }^{18} 2023$

We have focused only on the assessment of the instrument. This must be considered with the question of acceptability, effectiveness, and side effects of screening and treatment. Issues related to efficient organisation of the scheme should also be thoroughly assessed. For example, only $22 \%$ of those above the threshold for post-traumatic stress disorder in the US military were referred for further mental health evaluation. ${ }^{35}$ In both the US and UK militaries there remains considerable reluctance to admit to mental health problems because of stigma and the perception of negative effects on career. Until these are addressed, screening would continue to be ineffective.

We thank the UK Ministry of Defence for their cooperation; in particular we thank the Defence Medical Services Department, the Defence Analytical

\section{What is already known on this topic}

Since the aftermath of the first world war there has been an ongoing discussion on the benefits of screening military personnel for mental health vulnerability before deployment

\section{What this study adds}

Screening before deployment has a low predictability for most common mental health conditions

The predictability of screening for post-traumatic stress disorder is higher than for any other mental health problem

As the prevalence of post-traumatic stress disorder is low before deployment, screening for the condition would be inappropriate despite a moderately high predictability 
Services Agency, the Armed Forces Personnel Administration Agency, and the Veterans Policy Unit.

Contributors: RJR was principal investigator, planned and sought funding for the study, supervised data collection, designed the analysis, was the lead author, and is guarantor. RH collected and processed data collection, discussed and carried out the analysis, wrote the paper, and is guarantor. MJ and LH participated in the conduct of the research, analysis, and the writing of the paper. TB participated in the conduct of the study. $\mathrm{OH}$ was responsible for data management and participated in the planning and conduct of the study. DM participated in the planning and conduct of the study. MH was a principal investigator, sought funding, and participated in the planning, supervision of data collection, and writing of the paper. SW was principal investigator, sought funding, led the planning of the study and supervision of data collection, and made comments on the analysis and writing of the paper.

Funding: The initial study was funded by the Defence Science and Technology Laboratory (Dstl), part of the Ministry of Defence. The second survey was funded by the UK Ministry of Defence.

Competing interests: SW is honorary civilian consultant adviser to the British army.

Ethical approval: The initial survey was approved by the Defence Medical Services clinical research committee. The second study received approval from the Ministry of Defence (Navy) personnel research ethics committee and the King's College Hospital local research ethics committee.

1 Jones E, Hyams KC, Wessely S. Screening for vulnerability to psychological disorders in the military: an historical survey.J Med Screen 2003;10:40-6.

2 Shephard B. A war of nerves: soldiers and psychiatry 1914-1994. London: Jonathan Cape, 2000.

3 Implementation and application of joint medical surveillance for deployment. DoD Instruction No 6490.3, 1997. http://amsa.army.mil/documents/DoD_PDFs/ dodinstruct_implmnt64903.pdf(accessed 25 Jan 2005).

4 Wright KM, Huffman AH, Adler AB, Castro CA. Psychological screening program overview. Mil Med 2002;167:853-61.

5 Orr DW. Objectives of the selective service psychiatric classification. Bull Menninger Clin 1941;5:131-3.

6 Salmon T. The care and treatment of mental diseases and war neuroses ("shell shock") Salmon T. The care and treatment of mental diseases
in the British Army. Mental Hygiene 1917;1:529-30.

7 Sutton D. The utilisation of psychiatry in the armed forces. Psychiatry 1939;2:133.

8 Appel JW, Beebe GW, Hilger DW. Comparative incidence of neuropsychiatric casualties in world war I and world war II. Am J Psychiatry 1946;103:196-9.

9 Brill NQ, Beebe GW. Some applications of a follow-up study to psychiatric standards for mobilization. Am J Psychiatry 1952;109:401-10.

10 Bramsen I, Dirkzwager MA, van der Ploeg HM. Predeployment personality traits and exposure to trauma as predictors of posttraumatic stress symptoms: a prospective study of former peacekeepers. Am J Psychiatry 2000;157:1115-9.

11 Schnurr PP, Friedman MJ, Rosenberg SD. Preliminary MMPI scores as predictors of Schnurr PP, Friedman MJ, Rosenberg SD. Preliminary MMPI sco
combat-related PTSD symptoms. Am J Psychiatry 1993;150:479-83.

12 Norris RL, Maguen S, Litz BT, Adler AB, Britt TW. Physical health symptoms in peacekeepers: has the role of deployment stress been overrated? Stress Trauma Crisis 2005;8:1-15.

13 Egan J, Jackson L, Eanes R. A study of neuropsychiatric rejectees. JAMA 1951;145:466-9.

14 Aita J. Efficacy of brief interview method in predicting adjustment: 5 year follow-up study of 304 Army inductees. Arch Neurol Psychiatry 1949;61:170-8.

15 Plesset M. Psychoneurotics in combat. Am J Psychiatry 1946;103:87-90.

16 Sharp W. Fate of 395 mild neuropsychiatric cases salvaged from training period and Sharp W. Fate of 395 mild neuropsychiatric cases
taken into combat. Am J Psychiatry 1950;106:801-7

17 Ludwig AO, Ranson SW. A statistical follow-up of effectiveness of treatment of combatinduced psychiatric casualties. Mil Surg 1947;100:51-9.
18 Rona RJ, Jones M, French C, Hooper R, Wessely S. Screening for physical and psychological illness in the British Armed Forces: I. The acceptability of the programme.J Med Screen $2004 ; 11: 148-53$

19 Rona RJ, Hooper R, Jones M, French C, Wessely S. Screening for physical and psychological illness in the British Armed Forces: III. The value of a questionnaire to assist a medical officer to decide who needs help.J Med Screen 2004;11:158-61.

20 Hotopf M, Hull L, Fear N, Browne T, Horn O, Iversen A, et al. The health of UK military personnel who deployed to the 2003 Iraq war: a cohort study. Lancet 2006;367:1731-41.

21 Blanchard EB, Jones-Alexander J, Buckley TC, Forneris CA. Psychometric properties of the PTSD checklist (PCL). Behav Res Ther 1996;34:669-73.

22 Goldberg D, Williams P. A user's guide to the general health questionnaire. NFER-Nelson: Windsor, 1988.

23 Unwin C, Blatchley N, Coker W, Ferry S, Hotopf M, Hull L, et al. Health of UK servicemen who served in Persian Gulf War. Lancet 1999;353:169-78.

24 Ware J, Snow K, Kosinski M, Gandek B. SF-36 health survey manual and interpretation guide. Boston, MA: Health Institute, New England Medical Center, 1993.

25 Barbor TF, Higgins-Biddle JC, Saunders JB, Monteiro MG. The alcohol use disorders test: guidelines for use in primary care. 2nd ed. Geneva: World Health Organization, 2001

26 Jacobsen B, Hasvold T, Høyer G, Hansen V. The general health questionnaire: how many items are really necessary in population surveys? Psychol Med 1995;25:957-61.

27 Deeks JJ, Altman DG. Statistics notes. Diagnostic tests 4: likelihood ratios. BMJ 2004:329:168-9.

28 Hoge C, Castro CA, Messer SC, McGurk D, Cotting DI, Koffman RL. Combat duty in Iraq and Afghanistan, mental health problems, and barriers to care. $N$ Engl J Med Iraq and Afghan

29 Hoge CW, Auchterlonie JL, Milliken CS. Mental health problems, use of mental health services, and attrition from military service after returning from deployment to Iraq and Afghanistan. JAMA 2006;295:1023-32.

30 Barrett D, Gray G, Doebbeling BN, Clauw DJ, Reeves WC. Prevalence of symptoms and symptom based conditions among Gulf War veterans: current status of research findings. Epidemiol Rev 2003;24:218-27.

31 Bliese PD, Wright KM, Adler AB, Thomas JL. Psychological screening validation with soldiers returning from combat. In: Roy MJ, ed. Novel approaches to the diagnosis and treatment of posttraumatic stress disorder. Amsterdam: IOP Press, 2006:78-86.

32 Rona RJ, Hyams KC, Wessely S. Screening for psychological illness in military personnel. JAMA 2005;293:1257-60.

33 Brewin C, Andrews B, Valentine JD. Meta-analysis of risk factors for posttraumatic Brewin C, Andrews B, Valentine JD. Meta-analysis of risk factors for posttra
stress disorder in trauma-exposed adults. J Consult Clin Psychol 2000;68:748-66.

34 Solomon Z, Mikulincer M. Trajectories of PTSD: a 20-year longitudinal study. Am J Psychiatry 2006;163:659-66.

35 GAO Report to Congressional Committees. Post-traumatic stress disorder. DOD needs to identify the factors its providers use to make mental health evaluation referrals for servicemembers. GAO-06-397. www.gao.gov/cgi-bin/getrpt?GAO-06-397 (accessed May 2006).

(Accepted 23 August 2006)

doi $10.1136 /$ bmj.38985.610949.55

King's College London, King's Centre for Military Health Research, Weston Education Centre, London SE5 9RJ

Roberto J Rona professor of public health

Margaret Jones research associate

Lisa Hull study coordinator

Tess Browne research assistant

Oded Horn data manager

Dominic Murphy research assistant

Matthew Hotopf professor of general hospital psychiatry

Simon Wessely professor of epidemiology and liaison psychiatry

Imperial College London, National Heart and Lung Institute, Respiratory

Epidemiology and Public Health, London SW3 6LR

Richard Hooper lecturer in medical statistics

Correspondence to: R J Rona Roberto.rona@iop.kcl.ac.uk 